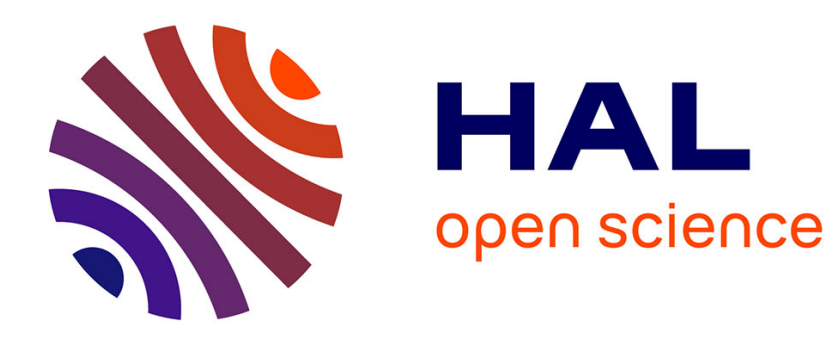

\title{
Identifying ontologies in a clinical trial
}

Charlotte Brives

\section{- To cite this version:}

Charlotte Brives. Identifying ontologies in a clinical trial. Social Studies of Science, 2013, 69, pp.1784

- 416. 10.1177/0306312712472406. hal-01528907

\section{HAL Id: hal-01528907 \\ https://hal.science/hal-01528907}

Submitted on 4 Jan 2021

HAL is a multi-disciplinary open access archive for the deposit and dissemination of scientific research documents, whether they are published or not. The documents may come from teaching and research institutions in France or abroad, or from public or private research centers.
L'archive ouverte pluridisciplinaire HAL, est destinée au dépôt et à la diffusion de documents scientifiques de niveau recherche, publiés ou non, émanant des établissements d'enseignement et de recherche français ou étrangers, des laboratoires publics ou privés. 


\section{Social Studies of Science}

http://sss.sagepub.com/

\section{Identifying ontologies on a clinical trial}

Charlotte Brives

Social Studies of Science published online 26 February 2013

DOI: $10.1177 / 0306312712472406$

The online version of this article can be found at:

http://sss.sagepub.com/content/early/2013/02/26/0306312712472406

Published by:

(9)SAGE

http://www.sagepublications.com

Additional services and information for Social Studies of Science can be found at:

Email Alerts: http://sss.sagepub.com/cgi/alerts

Subscriptions: http://sss.sagepub.com/subscriptions

Reprints: http://www.sagepub.com/journalsReprints.nav

Permissions: http://www.sagepub.com/journalsPermissions.nav

>> OnlineFirst Version of Record - Feb 26, 2013

What is This? 


\section{Identifying ontologies in a clinical trial}

Social Studies of Science $0(0) 1-20$

(C) The Author(s) 2013 Reprints and permission: sagepub. co.uk/journalsPermissions.nav DOI: |0.1 I77/03063|27|2472406 sss.sagepub.com

@SAGE

\title{
Charlotte Brives
}

Institut d'Études Politiques de Bordeaux, Domaine Universitaire, Pessac, France

\begin{abstract}
For a number of years, clinical trials have been the focus of a growing body of social science research and have come to represent the gold standard of evidence-based medicine. While a considerable and wide-ranging body of research has been devoted to trial participants, the approach is partial in that the participants' reality tends to be cut loose from the very practices that constitute the beating heart of the trials. The practices of clinical research tend to be accepted as an unquestioned premise from which myriad actions and consequences emerge. Following the praxiological turn initiated by Mol and basing my analysis on my fieldwork and an ethnographic account of the running of a clinical trial, I hope to propose a new reading of trial participation. Indeed, whatever their form or their objectives, trials are essentially scientific experiments and are invariably grounded in a clinical design. The individuals who take part in trials must also contend with these two types of practices - the clinical and the scientific - yet in terms of their significance for participants, the latter are often obscured by or reduced to the former. Using my account of a routine visit in a trial conducted in Burkina Faso, I would like to examine the specific nature of these research practices, and in doing so, identify the ontologies they involve. How do these practices do the body? And what might the consequences be?
\end{abstract}

\section{Keywords}

Africa, body, clinical trials, ethnography, HIVIAIDS, ontology

For a number of years, clinical trials have been the focus of a growing body of social science research and have come to represent the gold standard for evidence-based medicine (Marks, 2000; Timmermans and Berg, 1997). They play pivotal and essential roles in biomedical science, be it achieving marketing authorization for a new molecule, supporting the application of new uses for existing molecules, enabling certain populations to gain access to medical care or opening up new prospects for molecules about to enter

\section{Corresponding author:}

Charlotte Brives, LAM, UMR5I I5 CNRS - Institut d'Études Politiques de Bordeaux, Domaine Universitaire, II allée Ausone, 33600 Pessac, France.

Email: charlottebrives@gmail.com 
the public domain (Epstein, 2007). While some studies have been concerned with the limits of these designs (Cartwright, 2007), as well as with certain abuses in their application (Greene, 2007; Marks, 2000; Pignarre, 2003), a considerable and wide-ranging body of research has been devoted to trial participants themselves.

Studies conducted in diverse settings have thus explored the ethical issues surrounding biomedical research and, in so doing, have brought into sharp relief the variable character of these commitments (Hayden, 2007; Molyneux and Geissler, 2008; Petryna, 2005, 2009; Sariola and Simpson, 2010). A significant body of research has also been concerned with the way participants appropriate the trials they take part in: not only their health outcomes but also their concomitant resources, both in the context of HIV/AIDS research in the West (which enables subjects to benefit from the newest molecules at the earliest possible stage (Epstein, 2001)), and in low-resource settings (where trials not only represent a means of access to medication and care otherwise unavailable but also a way of accessing material resources such as phones, cars, clothing, etc.). Some participants also see trials as fulfilling a pivotal role in terms of identity politics and the recognition of specific statuses, yet also in constructing new subjectivities, and new self-conceptions, thus generating transformed ways of acting and living (Nguyen, 2010).

Although these studies invariably place trial participants at the centres of their analyses, the approach is partial in that the participants' reality tends to be cut loose from the very practices that constitute the beating heart of the trial. Indeed, whether concerned with ethical or identity issues, or with activism or access to care, these studies do not, generally speaking, apprehend their subjects in terms of their very adherence to the trial and to the practices making up the trial. The practices of clinical research tend to be accepted as an unquestioned premise from which myriad actions and consequences emerge.

Significant studies carried out in Science Studies, grounded in close observation of biomedical practices, have shown how these practices produce multiple objects diseases, bodies, technologies, molecules and even classifications (Berg and Mol, 1998; Bowker and Star, 2000; Greene, 2007; Hirschauer, 1991; Mol, 2002; Mol and Law, 2004) - and, in so doing, how they generate new identities for the individuals concerned, including multiple identities (Timmermans, 1996) and multiple life trajectories (Bowker and Star, 2000). However, these multiple identities should not be understood as the myriad facets of the same individual apprehended from shifting perspectives. Indeed, following Annemarie Mol's work and embracing what she refers to as a 'praxiological turn', I argue that these multiple identities convey multiple ontologies. In The Body Multiple, Mol breaks with the perspectivism pervading much social science research concerned with medicine, and, rejecting the configuration in which objects appear as elements onto which people project their different perspectives, she argues for an understanding of objects as things manipulated and enacted in practices (Mol, 2002). Drawing on her ethnographic research on the dayto-day treatment of atherosclerosis in the anonymized Hospital Z, she arrives at a particular analysis of the disease, apprehended not as a single disease presenting different aspects depending on the shifting perspectives of observation, but rather, as a multiple object engendering multiple realities. The clinician's atherosclerosis is not the same thing as the surgeon's atherosclerosis, and it is even further removed from 
the laboratory assistant's atherosclerosis. The different practices involve different individuals who do not share a common language or common techniques. Mol (2002) shows that reality itself multiplies, that the body becomes multiple, and she stresses that crucially at stake is the patient's very identity. To conclude, in her words, 'Different enactments of a disease entail different ontologies. They each $d o$ the body differently. But they also come with different ways of doing the good.' (p. 176, original emphasis).

Following the praxiological turn initiated by Mol and basing my analysis on my fieldwork and an ethnographic account of the running of a clinical trial, I hope to propose a new reading of trial participation. Indeed, whatever their form or their objectives, trials are essentially scientific experiments and are invariably grounded in a clinical design. Certain studies have already highlighted differences in approach between clinicians and researchers in the trial context or with research on certain diseases (Hales et al., 2001; Löwy, 2002). Other inquiries, taking a Latourian perspective, show how the process of research itself participates in regrounding practices - how the very organization and running of a trial influences clinical practices and reshapes behaviours and identities, and how the very process of producing findings facilitates their future diffusion, or 'extending the rails', to borrow Latour's eloquent expression (Petty and Heimer, 2011).

But what about the participants? The individuals who take part in trials must also contend with these two types of practices - the clinical and the scientific - yet, the latter are often obscured by or reduced to the former in terms of their significance for participants. Using my account of a routine visit in a trial conducted in Burkina Faso, I would like to examine the specific nature of these research practices and, in so doing, identify the ontologies they involve. How do these practices $d o$ the body? And what might the consequences be? These questions seem crucial if we hope to grasp these multiple dimensions of the individual and to reconnect issues often apprehended separately in the literature - bioethical issues, for example, or the diffusion of findings in relation to international guidelines or the implementation of large-scale health policies - since all of these issues are grounded (yet not resolved) in the very practice of clinical trials, which, by nature, straddle the clinic and the research sphere.

The data analysed in this article were derived from two periods of fieldwork in Ouagadougou, Burkina Faso, part of a wider project aiming to study clinical trials using two approaches often set apart from one another: medical anthropology and the anthropology of science. ${ }^{1}$ One of the central aims of the project is to reconnect research practices to the everyday experiences of the participants: How do these practices affect their everyday lives, their relationships with other people and the way they apprehend the care system and the medical staff? and What happens to the various actors when the trial ends? Moreover, how are the results produced and what are the consequences?

The trial aims to compare the effectiveness of two molecules in the prevention of mother-to-child HIV transmission during exclusive breastfeeding. During the fieldwork, I was able to observe, record and transcribe several dozen follow-up visits. I conducted interviews with the doctors, pharmacists, social workers and the trial nurse, as well as the clinical research associate and the scientific director. I also carried out informal interviews with the mothers who attended the clinic every morning with their children. 
The trial is conducted in the paediatrics hospital in Ouagadougou, in a special wing, separate from the other services. The mother-child pairs are referred by their primary health-care centre, meaning that the trial practices are completely separate, in geographical terms, from the local health-care system. To fully gauge the potential differences between care provision in the trial and care provision within the national health-care system, I undertook several observation sessions in three different centres - two located in Ouagadougou, and a third located several kilometres from the city, in bush country. I also conducted interviews with advisors working in these centres and observed and interviewed nurse/advisors who liaise between the trial and the national health-care centres. Another source of data was the weekly meetings held by the trial team, where issues connected not only to the trial but also to relations with the various health-care centres involved were discussed.

However, the descriptions and analyses presented in this article deal exclusively with the practices in the trial. The observations and data gathered on the national health-care system will thus be used in a more implicit manner, to sketch out a contrast with the data directly dealt with here. The substantial discrepancy between the national health-care system and the trial practices that we observe is real indeed, and it points up the very particular nature of the practices carried out in biomedical research. As Petty and Heimer (2011) argue, the practice of research tends to reshape clinical practices in developing countries to an even greater degree, insofar as these practices have to incorporate techniques, technologies and procedures that often have already been incorporated into clinical practices in the West. My intention is not to explore ground already covered by others, but to show how, in the day-to-day running of the trial, the medical staff and the participants have to grapple with these two kinds of practices. In this way, the apparently unequal balancing of this article conveys an endeavour to present these research practices in all their depth and complexity and, as a result, facilitate a better understanding of the ways in which they overlap with other kinds of practices, and in particular with clinical practices.

\section{Taking part in a clinical trial}

At the national paediatrics hospital in Ouagadougou, slightly removed from the other buildings and set apart, moreover, by a line of shrubs, lies a clinic running a medical trial that aims to assess the safety and effectiveness of two molecules, A and B, for the prevention of mother-to-child HIV transmission during exclusive breastfeeding. Just $4 \mathrm{~m}$ away from this building stands a shelter furnished with benches on which women sit and wait with their infants. There is not a single sign or notice that might reveal to an outsider what kind of activity is being conducted on the site. Indeed, in a country where HIVstatus continues to go relatively undiscussed between partners (Desclaux and Alfieri, 2009; Desgrées-du-loû et al., 2009; Makhlouf Obermeyer et al., 2011), a trial such as this one needs to be anonymous.

In Sub-Saharan Africa, there are just two existing solutions for preventing mother-tochild transmission (PMTCT) of HIV after delivery: infant formula feeding or exclusive breastfeeding with early weaning from the fourth month of life (WHO/UNICEF/UNFPA/ UNAIDS, 2007). The first is extremely costly, difficult to prepare and requires systematic 
use of uncontaminated drinking water and high sanitary standards. In addition to this, a mother who does not breastfeed her child may well excite suspicion and, as a result, stigmatization. Breast milk has a much more positive image: it stands not only for what is good for the child, for what is best for their immune defences, but also for what is best in terms of developing the mother-child bond. In the case of an infected mother, what is good for the child is also what could potentially cause the most profound damage, thus presenting a difficult-to-negotiate paradox.

The mothers waiting under the shelter have all made a decision: not only to breastfeed their infants, but also to abide by the numerous rules and regulations imposed by the study, and most often to go through the process alone. Indeed, the trial follows a simple but strict protocol: the infant receives two daily doses of medication, morning and evening, and must be fed exclusively with its mother's milk for the first 24 weeks of life (water is excluded, along with all other substances), a period after which complementary foods (solids) are gradually introduced into the infant's diet. Cessation of breastfeeding must occur at the latest in week 49 of participation in the trial, for the cessation of prophylaxis in week 50. The mother-child pairs must attend the clinic for regular follow-up visits and to give blood and milk samples for testing, which means they must stay in the city or its vicinity during the whole period of participation.

In the next sections of the article, I invite the reader to accompany Myriam and her son Marius during a routine follow-up visit. Myriam is a new mother of 30 years, and she has just separated from the father of her child. She arrived very early for her week 26 visit, before the other members of the trial. Her child has been part of the study for 6 months now. Today's visit is a special one for the mother-child pair: comprehensive physical examinations are scheduled to be carried out (not only viral loads and CD4 count but also full haematological and biochemical exams of the mother, serology and full haematological and biochemical screening of the infant), and Marius will, for the very first time, be able to try certain foods (baby cereal, fruit, soups, blended vegetables).

Myriam and Marius go in to see the social worker. This is the first stage of the process that they are now going through for the seventh time since their enrolment in the trial. Visits always follow the same routine: after the visit with the social worker, they will go on to see the doctor, and then they will go off with the nurse to do the tests in the laboratory (if it is a visit requiring lab tests), before going on to the pharmacist's room to collect their prescribed medication. Sitting opposite the mother and child, Juliette, the social worker, prepares the various documents she needs: the child's medical record, the observation sheet and the appointments register in which she scrupulously notes down all the points she must cover during the visit. Then she starts asking questions, always in the exact same order. She begins by asking Myriam whether the child has experienced any health problems since the last visit, whether he is feeding well and whether the exclusive breastfeeding has been kept to. Marius ran a slight fever recently, leading his mother to seek medical advice at the city's Centre de Santé et de Promotion Sociale (CSPS; Centre for the Promotion of Health and Social Wellbeing). The social worker goes on to enquire whether the child received treatment, and whether the mother remembered to bring the prescription and the relevant medication with her. Myriam hesitates, Juliette probes further, then Myriam ends up telling Juliette that she has not brought anything with her. 'You'll have to see about that with 
the doctor. And what about you? Are you well? Any problems? Any aching, any pain? Do you have any breast sores?'

Myriam is feeling well, she has no breast problems and only mentions tiredness linked to the exclusive breastfeeding and her child's increased appetite. She says she is delighted that he is 6 months old now and that she will now be able to start introducing certain solid foods into his diet. Juliette smiles, pinches Marius's chubby cheek to check the inside of his mouth for cleanliness, then, after making a few comments on the importance of keeping the tongue clean to prevent wounds and additional risks of contamination, turns back to face the mother to pursue the interview. She goes on to give Myriam some nutritional advice, stressing how important it is that Myriam maintain a good diet and that she rest as much as possible in order to keep healthy. She then goes on to list the different foods her child can start eating and how they should be prepared. Later on in the morning, when Myriam has completed the routine process, she will go back to see Juliette to learn how to prepare the baby cereal.

Finally, the social worker asks the mother about her menstrual cycle and sexual activity and pursues with some family planning advice. Has she chosen a method of contraception? Does she wish to have more children? Myriam does not know yet, her menstrual cycle has not yet resumed. Juliette stresses once more the importance of family planning and the unreliability of condoms as contraceptives. She then takes the child's medical record and the observation sheet (on which she has noted down all the information gathered during the interview) and takes the documents over to the doctor, followed by Myriam, Marius and myself.

Cyprien, one of the two doctors working in the trial, is sitting behind his desk with a wide smile across his face. While greeting us, he picks up a thermometer and mechanically places it under the child's armpit. Indeed, consultations always follow the same routine: after positioning the thermometer, he goes on to ask a few questions about the child's diet since the last visit and then about any potential infections that may have been contracted over this period, before proceeding with the examination and checking the baby's weight and measurements. This 'ritual', however well oiled, is typically disrupted to some extent by the participants' lives.

Indeed, in order for exclusive breastfeeding to be properly carried out, the mother must be with her child at all times. If, for instance, she leaves the child to go off to shop for groceries or, as in Myriam's case, to go to work, the infant is cared for by friends or family who, in most cases, are unaware of the situation. Because it is practically impossible to stop a mother-in-law (in Myriam's case) or aunt from giving a child water, it is difficult to fully adhere to the instructions given.

However, the greatest difficulties have to do with the infections the infant might contract. Marius suffered from a fever over the last month, leading Myriam to seek mainstream medical care. Before looking into the prescriptions, Cyprien interviews her for a few minutes to ascertain whether she consulted a marabout or witch doctor, or if she took her child back to the village. Did she, like many mothers, use medication that had been prescribed on a previous occasion? Did she, going on the advice of a neighbour or friend, buy medication from a street vendor? Although Myriam acknowledges that she sometimes uses street vendors for her own health needs, she maintains that for Marius, all she did was seek help at the CSPS. 'Even X [Juliette, the social worker] said so, that I mustn't 
go and see a witch doctor or a marabout. That I shouldn't see street vendors either if I wanted to stay healthy'. Cyprien checks the child's medical record to find the data recorded by the health-care professionals during her visit to the CSPS but finds no trace of the consultation. He asks Myriam whether any medication was prescribed and whether she has the prescription with her. As she had already told the social worker, she forgot to bring it with her. The doctor reiterates once again the importance of bringing anything to do with the child's health, and then turns to me to explain that it is unfortunately quite common for health-care professionals to not write anything in the medical record. The problem in the present case is that he has no information whatsoever about the infection nor any about the treatment administered to the child. The only solution is to ask the mother about the length of treatment, the list of drugs used and the dosage. For nearly 10 minutes, Myriam and Cyprien go through everything in minute detail, the latter repeating the same questions several times, checking and rechecking, for each drug, the start and end dates of treatment and appearing to be surprised by some of the doses Myriam details.

Liquid paracetamol, morning and evening, for seven days? Are you sure that is what you were told? Or did you think that if you gave it to him longer he would get better?

No, I was told seven days, I gave it seven days.

$\mathrm{Ah}$ !

Cyprien enters all these data into the electronic mother-child patient record. All the details must be recorded, everything that enters and leaves the child's body must be known.

He then asks the mother to undress her child so that he can proceed with the examination. Myriam busies herself, then rises from her chair, takes Marius's pagne (rectangle of cloth used as clothing) and briskly spreads it across the table; then she lays the child down and returns to her chair. After raising the cloth briefly to cover the infant's groin area in order to avoid a stream of urine (which does indeed come forth), Cyprien proceeds to examine Marius. He feels his head, he feels for lymph nodes, checks his eyes and feels his chest and abdomen, and he checks the groin area for lymph nodes, checks the genitalia and then examines the infant's legs and feet and between his toes. Then he takes his stethoscope to listen to his heartbeat, he sits the child up, listens to his lungs and checks his muscle tone. He turns to face Myriam to ask her whether he has started to crawl yet, adding that he is impressed by how strong Marius is. The examination takes about 5 minutes, then he proceeds to weigh the child. At only 6 months of age, Marius weighs $9.5 \mathrm{~kg}$. 'The wrestler', as the trial team call him, is thriving.

Cyprien calls Jean-Luc, the trial nurse, and asks him to proceed with the tests required for the week 26 visit. He tells Myriam to go with Jean-Luc now, as he has finished his check-up. We walk over to the test room that services the whole hospital, located at the other end of the complex. Jean-Luc takes two whole sample tubes of blood from Myriam, and two smaller tubes from Marius, who does not even flinch. Myriam, Marius and I then return to the clinic, while Jean-Luc takes the tubes and test sheets over to the hospital lab for testing. 
Under the shelter, five women are sitting waiting. The pharmacist is busy with another participant and cannot deal with Myriam's prescription immediately, so she sits down next to one of the other women. We have been talking for about 15 minutes, when the pharmacist comes to get us. Franck, one of the pharmacists working on the project, sits at his desk and takes the bottles of medicine Myriam has brought back (one of which still contains a small amount of product). He takes out various sheets relating to the child and to the medication prescribed. On one of the sheets, called 'adherence consultation sheet', he writes the date, the participant's identification number and the visit number. Then he places the three-quarter empty bottle on the weighing scales linked up to the computer. This simple gesture enables him to gauge the treatment adherence level, by measuring the number of remaining doses and comparing it with the number that should remain if the dosing has been strictly followed.

There are five main questions on the adherence consultation sheet:

1. Level of adherence.

2. Support from friends and family?

3. Storage of the medication and have instructions been followed?

4. Still motivated to pursue the study?

5. Difficulties encountered?

When the adherence result appears on the computer screen, Franck writes down '99 percent' next to the first question, that is, a very good result. As for the support received from family and friends, Marius's father is the only person who knows about the trial, but he plays no part in administering the medication. Myriam has, however, encountered a few difficulties in storing the medication under the proper conditions. It must be kept in a cool place - a refrigerator or a canari (earthenware recipient) - but Myriam had been forced to move and was unwilling to keep the medication where she is being lodged, and therefore left the bottle at Marius's father's home. She goes there whenever she can to take the required amount of medication and stores it in a syringe until she is due to administer the dose to her son. Franck explains that this is not satisfactory, mainly for sanitary reasons, and he provides her with a small empty bottle in which she can store the dose to be administered. He also asks whether her canari is still effective and, if not, says the clinic will cover the costs of purchasing a new one. The mother's high level of motivation is clear, and she and Franck consider the difficulties as minimal, but the pharmacist is careful to record all the data given.

He takes some new bottles, inscribes them with the visit number, the date and the dosage; takes a syringe, which is also new, and draws a line on it to indicate the precise quantity to be taken and administered to the child and then hands everything over to Myriam. After that, he fixes an appointment for the following month while reiterating his advice on correct adherence of the treatment regime and stressing once more the necessity of storing the medication according to the instructions.

The visit is now over. Myriam just needs to go back to see Juliette to be shown how to prepare the baby cereal mixture that Marius is now allowed to eat. The social worker takes a camping stove out and sets it up in the shade. She also takes a cooking pot and a packet of powder, and asks Myriam to take out the beaker, the bowl and the spoon that 
she had been asked to bring on the previous visit. She shows the mother the amount of water needed by drawing a line on the plastic beaker, then pours the water into the cooking pot. She adds three spoonfuls of powder and asks Myriam to stir while boiling for 5 minutes. Meanwhile, she explains that Myriam must use well water - not tap water stressing the sanitation standards. Once the cereal mixture is ready, Myriam feeds it to her son. She says that she is very happy to see him eat it all and welcomes the prospect of being able to get a little rest from now on.

Then Juliette asks Myriam to come and see her to give her the money to cover travel costs, and also so that she can write down the appointment date arranged with the pharmacist. After exchanging a few words, Myriam repositions Marius on her back and sets off. She has spent almost 3 hours at the clinic.

\section{Becoming an object of research}

This lengthy ethnographic description gives some idea of the everyday experiences of not only the mothers but also the staff working on the trial. The women quickly get into a routine. After one or two visits, they know exactly what they are expected to do and the time required for each interview, and they also know during which visits they or their child will be required to give blood samples. Some of the women arrive on those days looking more dispirited than usual, but they are always reassured when they see the nurse. I should state that the nurse - perhaps because he is the only staff member not to have a desk of his own to sit behind and ask more private and personal questions - is more or less the participants' confidant, the person they express their fears and hopes to.

Indeed, each mother-child pair is viewed as a specific case, with a particular life trajectory and distinct events. The quality of the health care and support provided and the social workers' attentiveness and willingness to help (e.g. each mother receives a prepaid mobile phone at the start of the trial, so that they can contact the social workers whenever they feel the need) mean that such particularities can be taken into account, enabling the clinic to provide outstanding conditions compared to the wider Burkinese health-care system. However, this exceptional centre is not the participants' sole health-care provider; most continue to come under the national health-care system as well. Indeed, although the trial protocol requests that mothers bring their children to the clinic if a problem arises, the clinic's opening hours (it is closed in the afternoons and at weekends) and the travel distance mean that mothers tend to seek help at their usual health-care centre instead. Moreover, it is mandatory that they carry on attending these centres for their child's vaccinations. The mother-child pairs therefore oscillate between two systems and two logics that, as the earlier description suggests, radically diverge.

\section{Responding to a biological question}

As mentioned in the opening sections of this article, a clinical trial is a scientific experiment mainly grounded in clinical practices. Clinical trials are the jewel in the crown of evidence-based medicine, based on the application of experimental science methods (Marks, 2000; Timmermans and Berg, 2003). One of the social workers working in the trial often explains to the mothers (summing up quite effectively the paradox this kind of 
study represents): 'What we want is your children. What we're interested in is your children, to find out which product, out of A and B, is the most effective' (Juliette, excerpt from an enrolment visit).

This is because the trial attempts to answer one simple clinical question: out of A and $\mathrm{B}$, which drug is the most effective and the safest for PMTCT of HIV during exclusive breastfeeding? Within this framework, and this is the crucial point that the social worker is making, the mothers are just as much a part of the experimental design as their infants, insofar as they bear responsibility for the physical welfare of their child.

Indeed, on enrolling in the project, the mother and child acquire a particular and complex status: they become actors in the experiment and must therefore fulfil certain exigencies. This is particularly evident in the enrolment procedure - which takes several hours to complete, two of which involve the social worker reading and explaining the inform consent forms ${ }^{2}$ in detail, using metaphors and examples. Great emphasis is laid on the mothers' responsibility, not only for their child but also for the wider community of people living with HIV. ${ }^{3}$

Mother and child indeed have a particular status because the trial's object of study is not the virus, the mother-child pair or even the molecules being tested for effectiveness, rather it is the interaction between the three. More specifically, the researchers' true object of interest is the very possibility of the virus entering the child's body, which is apprehended as a potential living host for the virus, an environment they attempt to control and modify through the introduction of the molecules. Although the body's response to the virus and/or treatment may vary from one child to another, the bodies still need to be compared, counted, added up and classified. For the data that are collected on each visit and during the trial as a whole to be used, bodies must become commensurable, they must share certain parameters. In other words, bodies must be standardized ${ }^{4}$ to the greatest extent possible.

Numerous studies emerging from Science Studies have demonstrated the importance of standardization in the production and diffusion of scientific findings, from the standardization of the living being (Fujimura, 1987, 1988, 1992; Hogle, 1995; Timmermans and Berg, 1997, 2003), to medical records (Berg, 1996, 1997; Berg and Bowker, 1997; Berg and Harterink, 2004;) and classification systems (Bowker and Star, 2000). These studies stress how the biological and medical sciences tend to objectify the human on the basis of select criteria or parameters. Yet, they also state that this reductive tendency often has the opposite effect of increasing creativity and diversity.

This necessary standardization should be the prism through which we try to grasp the project's activities as a whole. The social workers make sure that the infant is feeding well, that the mother is mindful of those surrounding her, that she makes sure that no one gives her child water or any solids before the sixth month of the infant's life and that the infant's mouth is always kept clean and free of sores, and likewise for the mother's breasts. These questions and this advice can be read as a way of ensuring the welfare of the mother and child, yet this is merely one level of interpretation. The second level positions the mother-child pair as the subject of a scientific experiment and, in this capacity, as objectifiable entities to be mastered and controlled (though this will to master and control is wishful thinking, as we will discuss later). The concern here is not about participants' welfare but about controlling participants as 'environments' - because, for 
instance, contaminated water and certain foods introduced too early can cause diarrhoea, thus encouraging the development of intestinal sores, which increase the risk of virus transmission.

Similarly, other illnesses and medical treatments might represent a danger for the child, and a loss of control in managing the parameters of the experiment. How can we ascertain that a noted side effect is due to the medication used in the trial and not to the treatment taken for an infantile illness? Were the molecules administered to the baby as part of health care compatible with those given in the trial? Was the illness for which the child was treated insignificant, or is there a connection to be made with the treatment the child is undergoing in the clinical trial? These questions require that the doctor have access to all the data, and that he be as precise as possible in his account of the events. To be able to get scientific results from these activities, all the parameters must be, if not mastered, then known down to the most minute detail.

The objectification of the mother-child pair is even more salient when one considers their visit with the pharmacist, where everything is a question of adherence. The support given by the family and the difficulties encountered are important aspects for the pharmacist in optimizing adherence. Indeed, insofar as the trial's purpose is to test the effectiveness of a molecule in modifying the environment of a potential living host for the virus, to make it unfit for the development of HIV, and insofar as the whole experiment is designed to assess the molecule's effectiveness, the key feature of the study continues to be its administration to the child. The family's awareness or lack of awareness of the mother's HIV-status and of the child's enrolment in the protocol has a crucial impact, both in terms of correct storage of the medication and the regularity of medication use. For the research to be successful, mothers need to be empowered and made very aware of their responsibilities; over the entire duration of the study, they receive a great deal of information about breastfeeding techniques, the modes of transmission and existing treatment. They also need to acquire new skills, for instance, memorizing everything the child ingests and regurgitates over a month-long period, memorizing any medication the child receives, the dosage and duration of treatment and abiding by the sanitary guidelines set out in the protocol in a context where this is no easy affair. An ambiguous responsibilization, presented as a responsibility towards the infants and other HIVinfected people - and this is clear during the enrolment process - is ultimately wholly about a responsibility towards ensuring the smooth running of the trial itself. From their enrolment and on each subsequent visit, the mothers are reminded of the importance of correct administration of the medication. Although the main reason given is of course a concern with the child's welfare, the second reason serves as a reminder of the mothers' role in the experiment: if the child should become infected during the breastfeeding period and adherence is not satisfactory, it will be impossible to determine the cause of infection. The main outcome of the study is the seroconversion rate during the trial; poor adherence jeopardizes the reliability of the data collected because it means that there is no basis on which to ascertain whether infection is caused by poor effectiveness of the medication or its irregular use.

Thus, taking a global perspective on the trial, the set of procedures and the relationships between caregivers and participants can and should be understood as the enactment of an endeavour to ensure, to the greatest extent possible, the validity of the scientific 
experiment. In other words, while the medical care provided to the mother-child pairs is of an exceptionally high standard - both in terms of the amount of time spent with each pair and the actual quality of the clinical care - the mother-child pairs are just one element in a larger experimental design: simultaneously living, consciously experiencing subjects and scientific objects.

\section{Managing emergencies}

The trial is not, however, hermetic to the wider context in which it is located. Not only, as we have seen, does its success depend to a large extent on the family and social situations of the mothers, but the trial is also inscribed in a national health-care system without which it would be unable to operate. Primary health-care centres are responsible for identifying the future mothers and referring them to the clinic when they meet the eligibility criteria; they will also receive the participants when the trial ends and they are also the providers that the mothers turn to when their children are ill, or are due for baby weight check-ups or vaccinations. Yet, the logics governing the two systems seem to diverge. The Burkinese health-care system is not only marked by a lack of funding and training but also by clientelism, corruption and, as people have to pay for treatments, inequities concerning access to care (Ridde, 2011). As some studies demonstrate, there are also problems linked to moral and social norms carried by the nursing staff themselves, the most striking one concerning single women with children. Whereas in the trial, single women inspire pity and empathy on the part of the social workers, they are often seen as delinquents or asocial in the health-care system, which emphasizes the father's role in reproductive health at every occasion (Ouattara et al., 2009).

It may seem obvious that the trial would fit uneasily with traditional Burkinese care and healing practices (which is why the social workers and doctors constantly remind the participants of the wrongdoings of witch doctors and healers ${ }^{5}$ ), but it might come as a greater surprise that, from time to time, it is also at odds with the Burkinese national health-care system.

Scientific experimentation is indeed based, among other things, on a system of notation, references and inscriptions - a 'cascade of inscriptions', to use Latour's expression (Latour and Woolgar, 1986). Writing is a crucial aspect of scientific experimentation. It provides a trace of the different events in an individual's life to later enable researchers to make inferences and validate hypotheses. The medical record - highly standardized in the Western context - fulfils a core role in the kind of context studied here, and it carries with it multiple ontologies (Berg, 1997; Berg and Harterink, 2004). Marius's medical record does not contain a single trace of his visit to the CSPS, where he was taken by Myriam during an episode of high fever. This is far from exceptional. It is, in fact, quite common for health-care professionals - through lack of staffing and funding, lack of training or simply because it is not habitual practice - to fail to record certain data. Indeed, when the patient arrives, the focus is on the weight and height (the first examination performed on a child on each visit to the CSPS), and this information is swiftly recorded. Unless the mother requests a further examination, the doctors typically move on to the next infant, for there are many others waiting - the wait before being seen is 
usually several hours, which affects other activities. However, the differences are not limited to the question of writing - crucial in one case and optional in the other. The way the patient's body is apprehended and the clinical practices carried out can also differ from one context to another, whether it has to do with the patient's medical history (rarely requested in the health-care centres but always taken into account in the trial context), or with the way the patient is treated.

Even the understanding of what constitutes an emergency is determined by the specific epidemiological context of each particular region or country. A malaria outbreak is a frequent occurrence in Sub-Saharan Africa, both for children and adults, and very often people will not bother going to a dispensary. However, something that, if treated in time, can be a minor medical episode or at least a banal episode in the wider Burkinese context becomes critical in the trial context.

Following Myriam's visit, I went to see Cyprien to discuss medical practices in and beyond the trial context. He explained to me that most often health-care professionals settle for treating symptoms, whereas he endeavours to find the cause connecting the various symptoms. Cyprien's stance stems from his status as 'doctor', from his professional career to date (his only other professional experience has been at the paediatrics hospital, which offers very satisfactory work conditions and health-care standards) and from his function in a clinical trial funded by a French research organization. However, the gap between the quality of care given in the trial context and the care given in the dispensaries is undeniable, and it masks a greater discrepancy between the practices themselves. While the trial endeavours to solve a scientific question and has at its disposal substantial resources for this purpose, the health-care centres attempt to manage emergencies and to deal with the most pressing cases, most often making do with what is at hand, managing the lack of supplies, the lack of equipment and the lack of space and time. While in the trial context a participant who has come for her routine followup visit will see no fewer than three or four different interlocutors, elsewhere, in the best case scenario there will only be one health-care professional to do both the listening (if they have a little time to spare) and the treating. Alternatively, the national health-care establishments often house a number of internationally funded programmes, and it is therefore quite common, in a CSPS, to be in contact with three different health workers. Each receives remuneration for their screening or advisory work on such and such disease; in such configurations, professionals tend to specialize and lose interest in the complaints that they are not trained in. In the context of the fight against HIV, this has significant repercussions: the health workers are not necessarily familiar with the PMTCT procedures, and it is not uncommon for women to fail to benefit fully, for this reason, from the treatment protocol. This explains why, when visiting the bush country centre, the advisor in charge asked which procedures should be carried out during labour and delivery and which molecules should be given, although she was responsible for overseeing all the women's medical care and screening and for delivering pre- and post-screening advice. The study revealed that while the women had access to treatment, they did not necessarily know why they were taking the medication nor the precise purpose of the treatment, as the health-care system is marked by the domination of medical staff over patients, who seem to merely undergo the medical treatments and interventions (Ridde, 2011). 


\section{From HIV-disease to HIV-virus, multiple ontologies}

The consequences of these discrepancies are far from insignificant for the mother-child pairs, and the repercussions do not stop at the comparison that the participants might make between the resources and services to which they ordinarily have access and for what they could legitimately hope - even though this awareness in itself could be quite brutal in many ways (Timmermans and McKay, 2009).

On the one hand, there is a high standard of health care, supplemented by the trial team's readiness and ability to listen attentively to the participant's concerns. From the child's very enrolment in the trial, the mothers are empowered and responsibilized. They receive targeted knowledge, something of which the social workers constantly remind them of in attempts to underscore the privilege the experience represents:

If you weren't part of the project, you wouldn't be getting all this information. And so this means that from today, you, and the women who didn't come here today, you're not going to have the same knowledge about HIV. True or false?

On the other hand, there is a national health-care system that cannot cater to the country's needs. The system is characterized by a shortage of qualified staff and insufficient training, namely with regard to care provision for HIV-positive patients. Thus, on the one hand, we have women who are being educated, women who understand the different stages they will be going through in the trial and women who, ultimately, actively participate in their own objectification and that of their child, and in their very construction as objects of biomedical research. On the other hand, we have women who are apparently subjected to a system, women who do not systematically receive the medical attention they require, to the point that some fail to return and become 'lost to follow up' - in other words, women who are simple objects in a system for which, as patients, they actually constitute the foundations.

Yet, drawing such conclusions oversimplifies. Participating in a trial does not only signify access to better qualified and more attentive medical staff who enjoy greater technical and financial resources, for the participation crucially involves new ontologies tied to the ways in which HIV itself is enacted. While HIV is apprehended as a disease in the health-care centres - and it continues to be a shameful, stigmatizing disease, often concealed from the infected person's sexual partner ${ }^{6}-$ in the trial context, it is enacted as a living entity able to pass from the mother's body to the infant's. In other words, the trial does not deal with disease or with symptoms, and while the mother's infection is monitored regularly, it is primarily to ensure that the infection still meets the trial criteria. The mothers are indeed asymptomatic, and are not undergoing treatment because their CD4 count is over the $350 / \mathrm{mm}^{3}$ of blood threshold. ${ }^{7}$ What gets enacted in practices in the trial context is the HIV-virus and not the HIV-disease. This has repercussions for all the actors involved. The medical staff have to learn to record the minutest of details, to fill out numerous forms and to manage the complex procedures that the trial entails, and this is not always a smooth process. I was able to observe the difficulty when a new social worker joined the team and struggled for months, not understanding why she was being reprimanded when she believed she was working appropriately, working as she had learned to do over the course of her studies and professional career. ${ }^{8}$ Indeed, the 
information relevant to her while she was talking with the mothers was of another kind than the information relevant for the trial. For example, she regularly forgot to do the blood testing or to fill in one or two forms because, as she said to me, this was not very important to her. What counted was the well-being of the individuals, not the milk or the blood storage, or the CD4 counts and the viral load. In other words, she was more interested in the feelings of the individuals than in the interactions between the virus and the bodies conceived as environments for this virus.

The participants themselves acquire new ontologies as they become objects of scientific research - elements in an experimental design whose scope extends far beyond them. From the clinical perspective, the infant is a patient whose health must be preserved at all costs, but in the experimental design of the trial, the infant is apprehended as a potential living host for the virus, an environment that the mother must ensure, through myriad means, remains unfit for the development of the virus. In this way, the mother acquires new skills and new knowledge, but she also adopts new corporeal practices: she must examine the condition of her breasts, and learn to clean her breasts and view each sore as a point of entry for the virus. Similarly, the mother must perform certain actions on her child: she must check the condition of his or her mouth and clean it with a bicarbonate-based solution. In this way, the trial produces, to a certain extent, the standards the women must meet in order to be 'good mothers'. In the course of the trial, even the molecules that are tested also acquire new skills: they might become capable of preventing the transmission of HIV from mother to child during breastfeeding. They are not yet treatments, just one aspect of the experimental design (Brives, in press).

All these elements signify that the trial itself is not and cannot be contained within the walls of the clinic: it unfolds across the city, in step with the mothers' and children's movements and day-to-day activities across that space. Nor, on a temporal level, are the research-related practices contained within the schedule of clinic visits. The mothers must administer medication twice a day and, throughout the day, adhere to the guidelines set out by the medical staff. Because the infant's body is a potential living host for the virus and because their mother's body is infected and - crucially - because they are participating in a trial, the way they live their lives is greatly affected, be it in their personal care (avoiding sores of any sorts, keeping the medication in good conditions), the mothering practices (e.g. not giving water or any solids before the 6 months of the infant's life) and their family and social relations (hiding things from the closest family members, not leaving the child with family members if they are not aware of the trial or the protocol). This lasts only for a while perhaps, but the changes these practices give rise to are very real indeed. Let us consider the issue of HIV-status disclosure among sexual partners: on every single visit, the trial social workers lay huge emphasis on the critical importance of participants disclosing their serostatus to their partner. Their intention is to improve the women's everyday lives, for them no longer to have to hide their condition and thus to increase treatment adherence and maximize the chances of preventing HIV infection in the child. Of course, the social workers are primarily concerned with the families' welfare, especially that of the children involved, but their relentless insistence is a product of the trial itself and the ontological regime it gives rise to.

In this way, for the entire duration of the trial, the mother-child pairs exist as research objects, yet not exclusively: they also exist as women, daughters/sons, employees, loved 
ones and so on. The trial might determine, in part, what choices the women make and impose numerous exigencies; yet, the women never emerge as passive objects, subjected to the authority of research. This is because the ontological regimes they negotiate are multiple, and there is thus no need to adhere to the interests or dimensions emphasized by the medical staff. In fact, the mothers tend to have a relatively unified goal: their child's treatment and their own; they act to gain access to quality care in a context of widespread precarity. This is not a problem as long as everyone sticks to the script, as long as everything fits together. However, what happens when this ontological regime fades away, when the trial disappears?

The practices of research enact HIV in a particular way: they are different from clinical practices and different, moreover, from the practices of non-governmental organizations (NGOs) or networks of people living with HIV. However, we are not dealing simply with differences in perspective here. The practices of research create multiple ontologies, for HIV and for the body. To use Mol's (2002) expression, already cited earlier in the article, 'they do the body differently'. However, following her a step further, 'they also come with different ways of doing the good' (p. 176). I thus argue that studying trials in practice delivers important insights into the ways in which objects are enacted, and it promises to be a valuable resource for future research. Trials are not isolated systems. They are experiments without borders (Jasanoff, 2006), and they also generate new meanings, new forms of interaction and new networks. In this way, following Latour's perspective, they participate in 'reassembling the social' (Latour, 2006). Consequently, we can no longer ignore the ontologies they produce and the way they interact with other ontologies emerging from the myriad trial-related practices (be it pharmaceutical, political, economic, ethical, medical or NGO-related practices). This article has shown how the trial participated in reshaping the lives of the mothers and their children and how it produced new identities and new ontologies. In other words, the clinical trial as a scientific experiment generates both the results and the objects required to obtain these results. This is a crucial point, and it is especially so for trials such as the one studied here, whose purpose is not only to establish new standards of treatment and care but also, as we saw, a standard concerning being a 'good mother', whereas the national health-care system sustains other kinds of ontologies and norms, including the 'good mother' being first the married one.

Indeed, the new World Health Organization (WHO) guidelines for PMTCT of HIV after delivery advocates exclusive breastfeeding for the first 6 months of life with prophylaxis, that is, precisely what was tested in the trial. However, in light of the present analysis, we might understand the issue of countrywide or continent-wide implementation of such care standards differently. The transition from research practices to medical practices is a process fraught with difficulties, particularly when the care providers involved have very little experience of biomedical research. This applies to the staff, to the implementation of new technologies and also to the patient-participant.

Many studies have demonstrated the huge difficulties involved in standardizing model organisms to reproduce the results in different laboratories ${ }^{9}$ (and these were studies dealing with relatively simple organisms compared to humans), thus revealing 
scientific replication to be a formidable and elusive goal indeed. In order to be able to use results generated by political or economic practices or by campaigning or NGO work, one needs first to attend to the kind of coordination work necessary for the alignment, albeit temporary, of the various ontologies involved and the various, concomitant ways of doing the good. This is a very important question when it comes to the South, where very different health policies, conducted by very different actors, and which carry very different ontologies, meet. In Burkina Faso, several trials about PMTCT were conducted in the last 15 years, and it is not rare to meet mothers who participated in two of them, including the one described here. However, these other trials were about the possibility of infant formula feeding to prevent the HIV transmission from mother to child. This kind of practice enacts HIV and the mother and child bodies quite differently than the one I studied here, in that it focuses on the contaminated milk and the necessity for the child health to avoid any contact with it. So, within a few years, mothers are alternatively good or bad ones, depending on the techniques at work. This has great repercussions, as some NGOs themselves distributed large amounts of milk in the past and explained for years to mothers that to breastfeed their children was wrong. We deal here with what Mol (2013) calls 'ontonorms', to refer to ontologies as well as normativities. The studied trial carries ontologies, and with it, ideals, goods and bads. Its generalization will inescapably have to deal with other norms, other ways of doing the good, and this refers to political questions.

Thinking in terms of multiple ontologies might help explain the successes and failures in implementing new norms and standards of care as they meet other ones. However, it might also help one understand a more general question: that of the human subject of research, at the heart of numerous writings about ethics, standards and dissemination of scientific knowledge. Indeed, as we saw, the subject of research does not exist before the beginning of the trial. He does not exist as such when he is asked to participate and to sign the informed consent form. It is only after this step, in the making, that the subject is shaped and shapes itself, like Myriam and her son, to help the trial's ontological framework. We saw how the mother was responsibilized and how the mother-child pair became in the process, good research subjects, which for Myriam means becoming a 'good mother'. Concerning the human subject, different ontologies meet but do not necessarily fit together, as the literature on bioethics often demonstrates. It is crucial today to think about these different ontologies of the human subject and how they meet. There is, for example, one constructed through the experiences of the past (the Nuremberg Code, The Declaration of Helsinki and the Belmont report to mention the most important elements), which is constituted as a standard and which postulates the existence of a universal, stable, human subject. There also are ones constructed in practice, different for each country; for each trial and, to some extent, for each individual. Thinking in terms of multiple ontologies permits us not only to recognize these questions but also to offer new perspectives to treat them.

\section{Funding}

This research received grant from the Agence Nationale de Recherche Sur le Sida et les Hépatites Virales (ANRS; French National Agency for Research on AIDS and Viral Hepatitis) 


\section{Notes}

1. Programme funded by the Agence Nationale de Recherches Sur le Sida et les Hépatites Virales (ANRS; French National Agency for Research on AIDS and Viral Hepatitis), titled 'L'essai clinique comme espace de rencontres. Des logiques scientifiques aux expériences individuelles: constructions des participants, biosocialité et expériences de Subjectivation (Abidjan - Côte d4ivoire), ANRS 12242'.

2. There are various forms: one for participation in the project, one authorizing the trial to draw samples of the child's blood and one authorizing storage of the mothers' milk samples and their possible use in future research.

3. For an analysis of trial inclusion procedures, see Brives (in press).

4. For a more detailed analysis of the overlapping of body/virus/molecules, see Brives (in press).

5. A vast majority of the population, including doctors themselves, as one of them told me, uses traditional healing practices. These are mainly witch doctors and various healers, and selfproclaimed preachers claiming their ability to cure people from HIV/AIDS.

6. On their enrolment in the trial, approximately 90 percent say that they have not disclosed their HIV-status to their sexual partner. One of the objectives of the social workers is to encourage the women to disclose their serostatus with a view to improve their daily lives, and also to increase treatment adherence for their child.

7. The current World Health Organization (WHO) guidelines stipulates initiation of treatment for people infected with HIV when their CD4 count goes over the critical $350 \mathrm{CD} 4 / \mathrm{mm}^{3}$ of blood threshold.

8. See Petty and Heimer (2011) for an excellent analysis of issues affecting medical staff.

9. See, for example, Kohler (1994), Ankeny (2001), Clause (1993), Creager (2002) and Rader (2004).

\section{References}

Ankeny RA (2001) Model organisms as models: Understanding the 'Lingua Franca' of the Human Genome Project. Philosophy of Science 68(3): S251-S261.

Berg M (1996) Practices of reading and writing: The constitutive role of the patient record in medical work. Sociology of Health \& Illness 18(4): 499-524.

Berg M (1997) Rationalizing Medical Work, Decision-Support Techniques and Medical Practices. Cambridge, MA: The MIT Press.

Berg M and Bowker G (1997) The multiple bodies of the medical record: Toward a sociology of an artifact. Sociological Quarterly 38(3): 513-537.

Berg M and Harterink P (2004) Embodying the patient: Records and bodies in early 20th-century US medical practice. Body \& Society 10(2-3): 13-41.

Berg M and Mol (eds) (1998) Differences in Medicine: Unraveling Practices, Techniques and Bodies. Durham and London: Duke University Press.

Bowker GC and Star SL (2000) Sorting Things Out: Classification and Its Consequences. Cambridge, MA: The MIT Press.

Brives C (in press).

Cartwright N (2007) Are RCTs the gold standard? BioSocieties 2(1): 11-20.

Clause BT (1993) The Wistar rat as a right choice: Establishing mammalian standards and the ideal of a standardized mammal. Journal of the History of Biology 26(2): 329-349.

Creager ANH (2001) The Life of a Virus: Tobacco Mosaic Virus as an Experimental Model, 1930-1965. Chicago, IL: The University of Chicago Press.

Desclaux A and Alfieri C (2009) Counseling and choosing between infant-feeding options: Overall limits and local interpretations by health care providers and women living with HIV in 
resource-poor countries (Burkina Faso, Cambodia, Cameroon). Social Science \& Medicine 69(6): 821-829.

Desgrées-Du-Loû A, Brou H, Tijou-Traoré A, Djohan G, Becquet R and Leroy V (2009) From prenatal HIV testing of the mother to prevention of sexual HIV transmission within the couple. Social Science \& Medicine 69(6): 892-899.

Epstein S (2001) La Grande Révolte des Malades: Histoire du SIDA Tome 1. Paris: Les empêcheurs de penser en rond.

Epstein S (2007) Inclusion: The Politics of Difference in Medical Research. Chicago, IL: The University of Chicago Press.

Fujimura JH (1987) Constructing 'do-able' problems in cancer research: Articulating alignment. Social Studies of Science 17(2): 257-293.

Fujimura JH (1988) The molecular biological bandwagon in cancer research: Where social worlds meet. Social Problems 35(3): 261-283.

Fujimura J (1992) Crafting science: Standardized packages, boundary objects and 'translation'. In: Pickering A (ed.) Science as Practice and Culture. London: The University of Chicago Press, pp. 168-211.

Greene JA (2007) Prescribing by Numbers: Drugs and the Definition of Disease. Baltimore, MD: The Johns Hopkins University Press.

Hales G, Beveridge A and Smith D (2001) The conflicting roles of clinicians versus investigators in HIV randomised clinical trials. Culture, Health \& Sexuality 3(1): 67-79.

Hayden C (2007) Taking as giving: Bioscience, exchange, and the politics of benefit-sharing. Social Studies of Science 37(5): 729-758.

Hirschauer S (1991) The manufacture of bodies in surgery. Social Studies of Science 21(2): 279-319.

Hogle LF (1995) Standardization across non-standard domains: The case of organ procurement. Science Technology \& Human Values 20(4): 482-500.

Jasanoff S (2006) Experiments without borders: biology in the labs of life. Public lecture at the London School of Economics, 15 June 2006. Available at: http:/www.lse.ac.uk/collections/ LSEPublicLecturesAndEvents/pdf/20060615 Jasanoff.pdf

Kohler R (1994) Lords of the Fly. Chicago, IL: The University of Chicago Press.

Latour B (2006) Changer de Société, Refaire de la Sociologie. Paris: La découverte.

Latour B and Woolgar S (1986) Laboratory Life: The Construction of Scientific Facts, 2nd edn. Princeton, NJ: Princeton University Press.

Löwy I (2002) Cancer de Chercheurs, Cancer de Cliniciens. Paris: Éditions des archives contemporaines.

Makhlouf Obermeyer C, Sankara A, Bastien V and Parsons M (2011) Genre et expérience du dépistage du VIH au Burkina Faso. In: Desclaux A, Msellati P and Sow K (eds) Les Femmes à l'Épreuve du VIH dans les Pays du Sud. Paris: ANRS, Collection Sciences sociales et sida, pp. 17-29.

Marks H (2000) La Médecine des Preuves, Histoire et Anthropologie des Essais Cliniques (1900 1990). Le Plessis-Robinson: Les empêcheurs de penser en rond.

Mol A (2002) The Body Multiple: Ontology in Medical Practice. Durham, NC and London: Duke University Press.

Mol A (2013) Mind your plate! The ontonorms of Dutch dieting. Social Studies of Science XXX (to be filled in on publication).

Mol A and Law J (2004) Embodied action, enacted bodies: The example of hypoglycaemia. Body \& Society 10(2-3): 43-62.

Molyneux S and Geissler PW (2008) Ethics and the ethnography of medical research in Africa. Social Science \& Medicine 67(5): 685-695. 
Nguyen VK (2010) The Republic of Therapy: Triage and sovereignty in West Africa's time of AIDS. London: Duke University Press.

Ouattara F, Bationo BF and Gruénais ME (2009) Pas de mere sans un 'mari': La nécessité du marriage dans les structures de soins à Ouagadougou. Autrepart 52: 81-94.

Petryna A (2005) Ethical variability: Drug development and globalizing clinical trials. American Ethnologist 32(2): 183-197.

Petryna A (2009) When Experiments Travel: Clinical Trials and the Global Search for Human Subjects. Princeton, NJ: Princeton University Press.

Petty J and Heimer CA (2011) Extending the rails: How research reshapes clinics. Social Studies of Science 41(3): 337-360.

Pignarre P (2003) Le Grand Secret de l'Industrie Pharmaceutique. Paris: La Découverte.

Rader K (2004) Making Mice: Standardizing Animals for American Biomedical Research, 19001955. Princeton, NJ: Princeton University Press.

Ridde V (2011) Politiques publiques de santé, logiques d'acteurs et ordre négocié au Burkina Faso. Cahiers d'Études Africaines 201: 115-143.

Sariola S and Simpson B (2011) Theorising the 'human subject' in biomedical research: International clinical trials and bioethics discourses in contemporary Sri Lanka. Social Science \& Medicine 73(4): 515-521.

Timmermans S (1996) Saving lives or saving multiple identities? The double dynamic of resuscitation scripts. Social Studies of Science 26(4): 767-797.

Timmermans S and Berg M (1997) Standardization in action: Achieving local universality through médical protocols. Social Studies of Science 27(2): 273-305.

Timmermans S and Berg M (2003) The Gold Standard: The Challenge of Evidence-Based Medicine and Standardization in Health Care. Philadelphia, PA: Temple University Press.

Timmermans S and McKay T (2009) Clinical trials as treatment options: Bioethics and health care disparities in substance dependency. Social Science \& Medicine 69(12): 1784-1790.

WHO/UNICEF/UNFPA/UNAIDS (2007) HIV and infant feeding: New evidence and programmatic experience. Report of a technical consultation held on behalf of the Inter-agency Task Team (IATT) on Prevention of HIV infections in pregnant women, Mother and their Infants, Geneva, Switzerland, 25-27 October 2006. Geneva: World Health Organization.

\section{Biographical note}

Charlotte Brives is post-doctoral researcher at the Laboratoire les Afriques dans le Monde (LAMUMR5115) at the Institut d'Études Politiques de Bordeaux. Her research focuses on the production of scientific facts, and more particularly on the relations established between researchers and what they call their 'research subjects' in the production of scientific evidence, be they human, as in clinical trials, or non-human, as it is the case in her doctoral research 'Of yeast and men, anthropology of relationships between humans and non-humans amongst a biology laboratory'. She is the author of several articles on subjects in clinical trials and the production of scientific facts. 